Verkaik, R., Francke, A.L., Meijel, B. van, Ouwerkerk, J., Ribbe, M.W., Bensing, J.M. Introducing a nursing guideline on depression in dementia: a multiple case study on influencing factors. International Journa of Nursing Studies: 2011, 48(9), 1129-1139

\begin{tabular}{|l|l|}
\hline Postprint Version & 1.0 \\
\hline Journal website & $\underline{\text { http://www.sciencedirect.com/science/article/pii/S0020748911000484 }}$ \\
\hline Pubmed link & $\underline{\text { http://www.ncbi.nlm.nih.gov/pubmed/21377678 }}$ \\
\hline DOI & $10.1016 /$ j.ijnurstu.2011.02.009 \\
\hline
\end{tabular}

This is a NIVEL certified Post Print, more info at http://www.nivel.eu

\title{
Introducing a nursing guideline on depression in dementia: A multiple case study on influencing factors
}

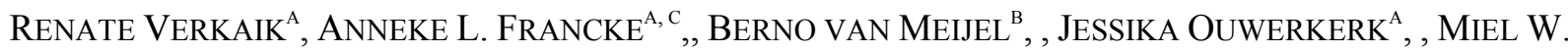 \\ RIBBE $^{\mathrm{C}}$, AND JOZIEN M. BENSING ${ }^{\mathrm{A}}$, \\ ${ }^{a}$ NIVEL, Netherlands Institute for Health Services Research, PO BOX 1568, 3500 BN Utrecht, The \\ Netherlands \\ ${ }^{\mathrm{b}}$ INHolland University for Applied Sciences, Research Group Mental Health Nursing, Amsterdam, The \\ Netherlands \\ ${ }^{c}$ VU University Medical Center/EMGO Institute, Amsterdam, The Netherlands
}

\begin{abstract}
Background: Successfully introducing care innovations depends on the type of care setting, the intervention and specific circumstances. In this study the factors influencing the introduction of an evidence based nursing guideline on depression in psychogeriatric nursing home residents were studied.

Methods: A mixed methods multiple case study design was used. The cases consisted of nine psychogeriatric wards participating in the intervention group of a controlled clinical trial. Eight types of data source (qualitative and quantitative) were used in the analyses. Triangulation of researchers, data and methods took place. Factors were categorized according to their organizational level: nursing home management (level 1), nursing team (level 2), CNAs (level 3), and residents (level 4).

Results: Factors influencing guideline introduction were mainly found at the levels of the nursing home management and the nursing team. Most factors concern stability of the organization and team (e.g. the inhibiting effects of reorganizations and other innovations), motivation (e.g. the facilitating presence of an opinion leader) and compatibility with current practice and vision (e.g. a facilitating emotion-oriented care vision). Factors influencing a successful application of the guideline are mainly found at CNA and resident level. At CNA level most factors relate to an emotion-oriented care vision (e.g. having a warm and creative personality). At resident level inhibiting factors mainly concern the residents' health status (e.g. feeling sick and/or having much pain). Important facilitating factors are positive attitudes of relatives and observing a reduction of depression severity.

Conclusions: Special facilitating factors for the guideline introduction and application seem to be the presence of a local opinion leader and the positive attitudes of relatives. Together they can motivate a nursing team in using the guideline. After a successful introduction of the guideline it's important to focus on its consolidation in daily practice.
\end{abstract}




\section{WHAT IS ALREADY KNOWN ABOUT THE TOPIC?}

- Introducing new guidelines or other care innovations into practice is no guarantee for success. Successful introduction seems to be most difficult in chronic care.

- Obstacles to use guidelines often arise at different levels of the health care system: at the level of the patients, the individual professional, the health-care team, the health-care organization or the wider environment.

\section{WHAT THIS PAPER ADDS}

- Factors influencing a successful introduction of the nursing guideline 'Depression in Dementia' are mainly found at the first two levels of the nursing home: nursing home management-level and nursing team-level. Factors influencing a successful application of the guideline are mainly found on the last two levels: CNA-level and resident-level.

- Next to the well known factors 'stability of the organization', and 'compatibility of the guideline with current practice and vision', other important factors regarding the introduction and application of the guideline are 'the presence of a local opinion leader' and 'a positive attitude of relatives'.

\section{INTRODUCTION}

Distribution of guidelines is often not enough to change the behavior of health care professionals. More effort is needed to implement guidelines into practice. However, which factors do influence the implementation either in a positive or negative way is not so clear yet, especially regarding guidelines for nurses or Certified Nurse Assistants (CNAs). In a systematic meta-literature review of Francke et al. (2008) existing literature reviews on factors influencing the use of clinical guidelines were analyzed. The main conclusion was that the evidence base is still thin, particularly as far as the implementation of nursing guidelines is concerned. The meta-literature review of Francke et al. (2008) points to the direction that environmental characteristics (e.g. support from peers or superiors), characteristics of professionals (e.g. familiarity with the guideline's content), patient characteristics (e.g. co-morbidity) and guideline characteristics all may influence the chance that guidelines are followed. Besides, implementation strategies with multiple components, e.g. training combined with feedback at the work floor, appear to be more effective than only one strategy. However, as said, the evidence base is still scarce, particularly with regard to guidelines for nursing staff.

In order to gain more insight into which factors play a role in the implementation of a nursing guideline in long term residential care we conducted a multiple case study in Dutch nursing homes ([Verkaik et al., in press-a] and [Verkaik et al., in press-b]). The implemented guideline 'Depression in Dementia' was directed to CNAs working on psychogeriatric wards. The data for the multiple case study were collected as part of a large multi-centre controlled clinical trial.

The research questions that are addressed in this paper are:

1. Which factors facilitate or inhibit successful introduction of the guideline in psychogeriatric nursing home wards?

2. Which factors facilitate or inhibit the successful application of the guideline by CNAs in their support of residents with comorbid depression?

\section{METHODS}

\subsection{Intervention}

The guideline was based on the principles of the BehaviorTherapy-PleasantEvents method as developed by Teri et al. (1997), which was shown to be effective in reducing depression in people with dementia still living in the community. Key elements of the newly developed guideline are (1) inducing individualized pleasant events, and (2) reducing unpleasant events. The guideline was developed according to the internationally validated AGREE criteria (AGREE Collaboration, 2003).

The strategies to introduce the guideline on each ward were multifaceted, consisting of (1) printed educational materials (guideline booklet, forms and training program), (2) interactive team training consisting of two training sessions and one follow-up session, (3) setting up of a promotion group. During 
the training sessions CNAs learned how to apply the guideline to their own residents by developing socalled individualized Pleasant-Activities-Plans. The training sessions were primarily aimed at CNAs, although the team manager, occupational therapists and psychologists working on the wards were also invited to participate. Non-certified nurse assistants were to be instructed by the trained CNAs themselves in between and after the training sessions. In this way the guideline was introduced to the complete nursing team.

A promotion group (in general a team manager, occupational therapist and two CNAs) was initiated on each participating ward in the experimental condition to facilitate and promote the application of the guideline. This team had the task of meeting every two weeks during the intervention period to discuss promotion and facilitation activities. The members of the promotion group were encouraged to consult the trainer during the introduction period, if they had any questions on the introduction or application of the guideline. Box 1 summarizes the intervention strategy.

\section{[BOX 1]}

\subsection{Participants}

\subsubsection{Nursing homes}

The participating nursing homes had applied in reaction to an invitation letter that was sent to 109 nursing homes in the central and western part of the Netherlands. Fifteen nursing homes applied that met the eligibility criteria. The participating homes were the first nine which applied and which met the following eligibility criteria:

(1) Having a minimum of two nursing teams working at two different but comparable psychogeriatric wards;

(2) the nursing teams do not work on each other's wards during the trial;

(3) the nursing teams are not yet applying any systematic methods that are comparable to the guideline;

(4) no reorganizations or other interventions have been planned for the wards that might interfere with the introduction of the guideline.

\subsubsection{Wards}

Of the nine participating wards, six were regular wards with on average 32 residents (range 30-40). Two wards were divided into two or three small scale living units, with 9 or 10 residents per unit. One ward was a traditional large scale ward with 60 residents.

\subsubsection{CNAs}

All 109 CNAs that worked at least $20 \mathrm{~h}$ per week on one of the nine participating wards in the experimental condition of the clinical trial were invited to participate in the training. In the Netherlands, CNAs provide most of the care on psychogeriatric wards and generally have three years of basic nursing training. They are more or less comparable - regarding educational level and skills - to Licensed Practical Nurses in the United States. Non-certified nurse assistants (helpers) were not invited because they were not previously educated in developing care plans.

Of the 109 invited CNAs 98 participated in the training. Reasons for not attending were pregnancy leave $(n=1)$, illness $(n=1)$, vacation $(n=1)$, only working night shifts $(n=3)$, arguments with the team manager $(n=1)$ and changing jobs $(n=4)$. The mean age of the trained CNAs was 37.6 years (SD 9.9) and 6\% were male. Mean working hours per week were 28.1 (SD 6.7), mean years in psychogeriatric care, 8.5 (SD 6.7) and number of working years on the ward, 5.6 (SD 5.5).

On every ward the CNAs that were the most and the least positive about the training were asked for an interview about the guideline introduction and application. It was decided to interview CNAs with extreme opinions because these were expected to provide the most insight into the facilitating and inhibiting factors. Depending on availability in every home (convenience sampling), at least one most positive and one least positive CNA was interviewed. In total 20 interviews took place (ten most positive; ten least positive). The second column of Table 1 shows the average score attributed by the CNAs to the training, including the minimum and maximum score that was given. The overall average mark was 7.27. Two of the CNAs who 
were interviewed were also member of the promotion groups on their wards. These two CNAs both represented CNAs who were the most positive about the training. There were no significant differences between the background characteristics of CNAs who were interviewed and those who were not $(p \geq 0.05)$.

\section{[TABLE 1]}

\subsubsection{Residents}

The guideline was used for 62 residents on the nine wards who were diagnosed by the nursing home physician and/or psychologist as being demented (DSM-IV-PC: APA, 1994) and depressed (PDC-dAD: Olin et al., 2002). Residents with severe dementia (Global Deterioration Scale stage 7; Reisberg et al., 1982) were excluded from the study because the intervention was aimed at residents who were still able to verbally communicate. Residents who were supported with the guideline had a mean age of 83.4 (SD 7.2); $73 \%$ had moderate or moderately severe dementia; $50 \%$ had resided between one and three years on the ward and $26 \%$ longer than three years.

\subsection{Data collection}

Data were collected using a multiple case study design in which the cases consisted of the nine wards on which the guideline was introduced. Characteristics of a multiple case study are that (a) data are collected and analyzed at different levels (e.g. nursing home management, nursing team, CNAs and residents), (b) several types of data collection are used (e.g. interviews, observation), and (c) a phenomenon is analyzed within its original context (Strauss and Corbin, 1998). This design allows data and methodological triangulation ([Denzin, 1978] and [Teunissen, 1985]) and the combining of qualitative and quantitative data. Data collection took place via eight data sources.

The interviews with the promotion groups and with individual CNAs were semi-structured and focused on (1) the success or failure of the introduction and the actual application of the guideline, (2) facilitating and inhibiting factors. Topic lists were used to loosely structure the interviews (see Box 2). The interviews were conducted by the first author (RV: psychologist) and a research assistant (a student of nursing science). All interviews were tape-recorded and then transcribed verbatim. The average length of the group interviews was $1 \mathrm{~h}$, the average length of the individual interviews was $20 \mathrm{~min}$.

\section{[BOX 2]}

In addition we studied memos by the researcher describing agreements with nursing home management of the participating homes, made in meetings before the study and intervention period started. The memos also described specific situations (e.g. regarding care vision, recent training courses) in the nursing homes.

In addition, evaluation forms were analyzed. At the end of the third training session each participating CNA filled out an evaluation form about their experience, containing 17 items. Information was gathered about clarity, usefulness, practicability and motivating aspects of the training. CNAs were also asked to score their level of appreciation of the training on a scale from 0 (very low) to 10 (very high).

Furthermore, the number of Pleasant-Activities-Plans that was present in the residents' care files two weeks after the follow-up training was counted. According to explicit instructions in the guideline and the training program, CNAs had to put the Pleasant-Activities-Plans into the residents' care files after they evaluated them.

Training reports were also analyzed. All training sessions on the nine wards were attended by the first (RV) or the fourth author (JO: research assistant). For every session, a training report was written afterwards.

Reports on observations of residents and their interactions with CNAs and others were analyzed as well. These observations were made by the fourth author (JO) on three occasions: just before the first, after the second, and after the follow-up training. Observations at different times made it possible to record possible changes in residents and their interactions. For practical reasons it was only possible to commence observation on the five wards to which the guideline was introduced last. On each of these wards between two and four residents were observed, depending on the number of residents participating in the clinical trial. In total 16 residents were observed. Different stages of dementia were included in the selection of 
residents, in order to be able to observe possible differences between stages. Observations focused on mood, behavior and interactions of the residents with CNAs, other residents and relatives. Specific observation times were: morning care, meals, recreation and personnel shifts. An observation protocol with points of interest and observation times was used to structure the observations. The observer took notes during the observations and if necessary made verbal memos on audiotape directly after an observation was finished. Afterwards the memos were transcribed.

Background characteristics of CNAs participating in the training and the interviews were derived from the baseline measure of the intervention study, and were analyzed as well.

\subsection{Analysis}

In order to answer the two research questions we used the following method of analysis.

First the level of success of the introduction of the guideline on each ward was derived. The "successful ward" variable was constructed around three variables that formed the core of the intervention: the training, developing Pleasant-Activities-Plans, and the promotion group activities. We chose to operationalize these variables with quantitative measures:

(1) the average score the CNAs awarded to the training on the evaluation form (one item) (scores $\geq 7.5=1$ point; $5-7.5=0$ points; $<5=-1$ point);

(2) the percentage of residents for whom a Pleasant-Activities-Plan was put in their care files after the follow-up training $(\geq 70 \%=1$ point; $50-70 \%=0$ points; $<50 \%=-1$ point $)$;

(3) the number of times the promotion group met ( $\geq 1=1$ point).

The variables were attributed equal weight because they were considered to be of equal importance for a successful guideline introduction. A composite score was calculated ranging from -2 to 3 . Wards with a score of 2 or 3 were considered successful, with a score of 1 moderately successful, and a score between 0 and -2 not successful.

Second, the texts of the transcribed interviews with the promotion groups, individual CNAs, memos of first meetings with nursing home management, training reports and reports of resident observations were imported into MaxQDA (VERBI Software, 2007). MaxQDA is a software tool specifically developed for qualitative data analysis. In MaxQDA the texts were read through several times. Facilitating and inhibiting factors were identified by closely looking at the factors mentioned by the promotion groups and individual CNAs to the questions 'What helped to introduce and apply the guideline/the Pleasant-Events-Method?' and 'What hampered the introduction and application of the guideline/the Pleasant-Events-Method?' Additional factors were identified by studying differences in organizational characteristics between successful, moderately successful and not-successful wards. Each text fragment was assigned one or more code words (Strauss and Corbin, 1998). All the code words were based directly on the content of the fragments.

Third, using the coded text fragments, the first author analyzed which facilitating and inhibiting factors differed between the wards that were most successful, moderately successful and not successful. To improve the quality of the analysis, five of the interviews with promotion groups and ten of the interviews with individual CNAs were also analyzed by the research assistant (JO) separately (researcher triangulation). Mutual codes and results of the analyses were compared and discussed. There were no disagreements about the most important facilitating and inhibiting factors or their specific nature.

Fourth, the coded text fragments of the observation data were analyzed to find out which patient characteristics that facilitate or inhibit guideline application.

Fifth, in order to analyze if background characteristics of CNAs working on a ward were related to the success of the guideline introduction, we performed Chi-square tests and ANOVAs in which the level of success was the dependent variable (none, moderate, high) and the CNA characteristics the independent variables (e.g. level of education, mean age and working hours per week).

Finally, all facilitating and hampering factors resulting from the eight data sources were related to one or more of the levels: nursing home, ward, CNA and resident level. To determine the relative importance of the facilitating and hampering factors, we analyzed which factors were present on the successful wards, the moderately successful and not-successful wards. Important facilitating factors were present on the successful wards and not on the moderately and not-successful wards. Important hampering factors were present on the not-successful wards and not on the moderately successful and successful wards. 
Verkaik, R., Francke, A.L., Meijel, B. van, Ouwerkerk, J., Ribbe, M.W., Bensing, J.M. Introducing a nursing guideline on depression in dementia: a multiple case study on influencing factors. International Journa of Nursing Studies: 2011, 48(9), 1129-1139

\subsection{Medical ethics and informed consent}

The intervention and measures of the controlled clinical trial as well as the case study activities were approved by the Dutch Central Committee on Research involving Human Subjects (CCMO). On behalf of all participating residents, legal guardians gave their informed consent for the intervention, measures and observations. The study took place from March 2005 to May 2007.

\section{RESULTS}

\subsection{Success of the guideline introduction}

Table 1 provides the scores of the nine nursing home wards on the variable 'success of the guideline introduction'. The last column in Table 1 shows the division of the nine wards into three groups:

(1) successful wards (nos. 1-3);

(2) moderately successful wards (nos. 4-7);

(3) unsuccessful wards (nos. 8 and 9).

\section{[BOX 3] [BOX 4]}

\subsection{Factors that relate to a successful guideline introduction and application}

Factors that play a role in the guideline introduction appear to exist on two levels: (level 1) nursing home management, and (level 2) nursing team. The factors on these levels interact with those that play a role in the guideline application on level 3 (CNAs), and level 4 (residents). The specific inhibiting or facilitating factors on the different levels are described below.

\subsubsection{Level 1. Nursing home management}

Inhibiting factors:

- Reorganizations or other innovations at the time of the guideline introduction.

In the nursing home of ward no. 7 a large-scale reorganization had taken place that was not yet finished at the time the guideline introduction started. Before the reorganization the team manager had an office on the ward, whereas the new manager took office in another part of the nursing home, away from residents and caregivers. The team had to become self-steering. The commotion this created in the team left little room for the introduction of the guideline. On ward no. 6 at the same time 'living in small units' was implemented. This overload of new information and methods made it difficult for the teams to focus on the guideline introduction. Despite agreements that were made with the nursing home management, on ward no. 9 a new reporting system and another training course were initiated simultaneously with the guideline introduction. This resulted, for example, in no Pleasant-Activities-Plans being put into the residents' care files.

- Top down introduction of the guideline.

CNAs of ward no. 7 were critical beforehand regarding the guideline introduction on their wards, because of reorganizations in the nursing home and their team, and a shortage of certified personnel. Despite this, the management of the nursing home decided to participate. The CNAs felt they were not sufficiently involved in the decision making, and this caused much resistance at the beginning of the guideline introduction and slowed down the implementation process.

\subsubsection{Level 2. Nursing team}

Facilitating factors:

- Presence of an opinion leader: a respected person who is connected to the ward and encourages, motivates and supports the whole team in using the guideline.

In the nursing home of ward no. 1, a psychologist working on the ward motivated the entire team in using the guideline and proposed creative solutions for practical problems. According to the promotion group and individual CNAs she was 'super enthusiastic' and a real motivator. Likewise, on ward no. 2 there was a psychiatric nurse who had a very stimulating role. He had the task of introducing 'emotion-oriented care' in the nursing home and considered the guideline introduction to be part of this. He devoted himself to making it a success. For example, he organized a meeting to inform the non-certified nurse assistant and other 
nursing helpers about the guideline. On wards no. 3-9 there were no persons that took the position of opinion leader

- Having a reporting system that the guideline fits into.

The successful wards (nos. 1-3) all mentioned that the Pleasant-Activities-Plans and related reporting fitted in well with their existing reporting system. On the other wards this was mostly not the case. There the introduction of the guideline was thought to incur additional paper work.

Inhibiting factors:

- Team manager does not recognize relevance of guideline introduction.

Only a team manager who is convinced of the importance of the guideline will facilitate and motivate his/her team to use it. A team manager who is not convinced, will give priority to other tasks or methods. On ward no. 8, one of the two unsuccessful wards, the team manager did not see the relevance of the guideline. This team manager was new in the nursing home and did not work there at the time the nursing home management and team managers made the decision for the guideline introduction. On this ward the introduction was limited: Pleasant-Activities-Plans were made, but were not based on new observations or life history information and were hardly applied.

- High staff turnover.

On ward no. 5 five CNAs departed their jobs during the guideline introduction. Some of these CNAs had taken the Pleasant-Activities-Plans that they developed with them instead of leaving them in the residents care files or with colleagues. Also their knowledge and (sometimes very special) relationship with the residents were gone.

- Shortage of certified personnel.

Ward no. 9 as well as ward no. 7 had a very high shortage of CNAs at the time of the guideline introduction. The promotion groups and individual CNAs on these wards indicated that this impeded the guideline introduction significantly.

A calculation was made of the CNA-resident ratio within the team. The results also point in the direction that sufficient certified personnel is needed: the highest CNA-resident ratio was found on the ward where the guideline introduction was most successful: this ratio was .6. The lowest ratio was found on the ward where the introduction was least successful; here the ratio was .2.

- Not sharing an emotion-oriented care vision.

On ward no. 4 the CNAs indicated that there was a division between young CNAs who really wanted to work in an emotion-oriented way and older CNAs who worked in a more task oriented manner and claimed that they did not consider the application of the Pleasant-Activities-Plans to be part of their job. The introduction of an emotion-oriented care method on this ward divided the two groups even more. They blamed each other for spending their time on the wrong tasks.

- The view that depressed residents should not have more privileges than non-depressed residents.

Wards no. 8 and 6 shared the opinion that residents with comorbid depression and dementia should not have more privileges than demented residents without depression. On ward no. 8 there was a real resistance against the individual activities and support for the depressed and demented residents. On ward no. 6 this attitude caused CNAs to try and involve non-depressed residents in the individualized activities of the depressed and demented.

- The expectation that the guideline and training would bring instant solutions for depression in dementia.

Ward no. 8 had the expectation that the guideline introduction would bring instant solutions for residents with comorbid depression and dementia and the sometimes related behavioral problems. They also had not expected that they had to develop Pleasant-Activities-Plans themselves. These expectations inhibited the guideline introduction extensively.

Inhibiting characteristics:

- The fact that non-certified or non-registered nurses or nursing assistants were not trained.

All nine wards had difficulty in informing the untrained members of the team about what was learned and agreed in the training sessions. According to the CNAs this had to do with (a) disappointment and misunderstanding among non-certified team members about not being trained, and (b) difficulties on the part of the CNAs with explaining the content of the guideline to their non-certified colleagues. From the observations of residents and their interactions with CNAs it became very clear that the non-certified or non-registered nurses or nursing assistants indeed contributed very little to the application of the guideline. 


\subsubsection{Level 3. CNAs}

Analysis of the influence of background characteristics:

The possible relationship between the success of the guideline introduction and background characteristics of the CNAs from the nine wards was statistically analyzed. Characteristics that were studied were: mean age, gender, educational level, current position, type of contract, working hours, years in psychogeriatrics and years on the ward. No significant relationships were found $(p \geq 0.05)$.

Facilitating characteristics:

- Warm and creative personality.

On all successful and moderately successful wards in the interviews with promotion groups and individual CNAs the names of one or more CNAs were mentioned that were very successful in applying the guideline. These CNAs were always described as warm and creative, enjoying one-to-one contact with residents. Having a sense of humor is also often mentioned as one of their characteristics.

- Sharing interests with resident.

Some CNAs had a very special relationship with one or two residents. This seemed related to sharing a major interest like, for example, religion. One CNA on ward no. 5 developed a complete PleasantActivities-Plan around religious activities, like psalm singing and Bible reading. A difficulty in these cases was that other CNAs could not always help in applying the plans that were (partly) built on the personal interests and relationships.

Inhibiting characteristics:

- The view that 'a resident has the right to be depressed'.

In some interviews CNAs expressed the opinion that in old age, after a long and sometimes difficult life, one has the right to be depressed. In their opinion one should not make much effort to change this.

- Employment: small contracts and alternating shifts.

When working less than $32 \mathrm{~h}$ a week it seems more difficult for CNAs to really get to know their residents, which is important for proper application of the guideline. Also working in different shifts hampers CNAs from keeping themselves informed about changes in residents. With small contracts and alternating shifts, CNAs largely depend on written reports, which often lack information on non-medical subjects.

\subsubsection{Level 4. Residents}

Facilitating factors:

- Visible reduction of depression.

According to the CNAs, the factor that had the most motivating effect on guideline application and further introduction of the guideline was perceiving positive effects on depression. Immediate and lasting effects had the most stimulating impact. If no effects on depression were perceived, this had an inhibiting effect on the application of the guideline to the individual resident and sometimes on the further introduction of the guideline. This seemed to be related to the expectations of CNAs and nursing teams about the guideline introduction and its effects. If they expected instant effects and quick solutions for the depression, they were soon disappointed and inhibited in further application and introduction.

- Positive attitudes of relatives.

On ward no. 1 there was considerable willingness among relatives to provide life history information. This not only facilitated the development of Pleasant-Activities-Plans, but also worked in a very stimulating way for the CNAs. The same counts for relatives providing photo albums or videos of family events, like weddings. The reactions of relatives to positive results of the guideline application were also perceived to be very motivating. On ward no. 9 many of the relatives did not want to provide the CNAs with life history information of their family members, probably because of prior negative relationships. According to the CNAs it was therefore very difficult or impossible to develop individualized Pleasant-Activities-Plans.

Inhibiting factors:

- Stage of dementia $>6$.

Before the guideline introduction the guideline was already considered unsuitable for people with severe dementia. The analyses confirm this view. It shows that for residents whose cognitive functions declined rapidly during the study period most activities that were developed were no longer applicable. Residents 
reaching the last stages of dementia could not, for instance, even concentrate on television programs about a favorite subject anymore.

- Multiple behavioral and emotional disturbances.

CNAs reported that for residents with aggressive or agitated behaviors and strong mood fluctuations, or with a history of major depression or schizophrenia, it was more difficult to apply the guideline. With these residents it was, for example, more difficult to plan activities for a specific date or time. In these cases CNAs seemed to need more creativity, flexibility and help from psychologists and others.

- Feeling sick/having much pain.

In some cases residents suffered from (new) somatic complaints during the period of the guideline introduction. If a resident felt sick or had much pain, undertaking activities with him was not possible. For some residents this meant that they could not be assisted according to the guideline for quite a while, which inhibited its success.

The answers to research questions 1 and 2, about factors related to the successful introduction and application of the guideline on the ward are summarized in

\section{[TABLE 2.]}

\section{DISCUSSION}

\subsection{Inhibiting and facilitating factors}

In this paper factors influencing a successful introduction and actual use of the nursing guideline 'Depression in Dementia' were studied. The guideline introduction proved to be successful on three of the nine participating experimental wards, moderately successful on four of these wards and not-successful on two wards. Factors influencing the guideline introduction and application were categorized on four levels: nursing home management (level 1), nursing team (level 2), individual CNAs (level 3) and individual residents (level 4). Factors facilitating or inhibiting a successful introduction mainly lay at the level of the nursing home management and the nursing team. Some of these factors are known from previous studies, and have to do with the (in-)stability of the organization (e.g. reorganizations) and the stability of the nursing team (e.g. staff turnover rate) (e.g. [Francke et al., 2008], [van Weert et al., 2004], [Schrijnemaekers et al., 2002] and [Holtkamp et al., 2001]). Other influential factors are less well known and/or may be specific for nursing guidelines characterized by a tailored-approach in which the individual preferences and emotions of a client form a point of departure. A factor which may be specific for this type of nursing guidelines is that a shared 'emotion-oriented' care vision at nursing team level facilitates a successful introduction.

In addition, our study also shows that the support of a respected local opinion leader, who is well acquainted with the content of the guideline and who sees it as his/her job to make the introduction a success, is a crucial success factor. The importance of such a local opinion leader has not been described so clearly in previous work, although it was already known that support in general (from peers or superiors) may be important (e.g. Francke et al., 2008).

The finding that a local opinion leader is important fits with what Rogers (2003) describes in his work on innovation processes. Innovation processes usually include top-down, management driven approaches in which current practices are reviewed and basically redesigned. Often an opinion leader within an organization coordinates and promotes the innovation process. Although the content of the guideline 'Depression in Dementia' focuses on the implementation of a new care method (the Pleasant-EventsMethod), the larger picture concerns the re-organization of the care process for depressed and demented residents. Prior to the guideline introduction, psychosocial support plans were usually developed by psychologists in collaboration with CNAs. After the guideline introduction these roles were switched.

The fact that most influencing factors that were found in this study are well known from 'theories of integrated care' suggests that change processes for nurses and CNAs in long term care are not different from change processes in other care settings.

Factors influencing a successful actual application of the guideline were mainly found on the level of the individual CNAs and residents, e.g. the involvement of relatives in facilitating and executing pleasant activities. The importance of involving relatives in caring for psychogeriatric nursing home residents has 
been underlined in earlier studies. Foley et al. (2003) and Radar and Tornquist (1995) showed that family support and involvement can assist CNAs in reducing residents' behavioral and psychological problems by helping to identify unmet medical, emotional or social needs. Robison et al. (2007) and Port et al. (2001) showed that the involvement of relatives positively influences the quality of care for residents.

\subsection{Strengths and limitations of a multiple case study design}

With a multiple case study design it was possible to look at the facilitating and hampering factors for a successful guideline introduction and application from different perspectives. Using data from nine wards in different nursing homes enhanced the completeness and transferability of the results, and made a comparison between successful and not successful wards possible. Using data from multiple sources and methods enhanced the validity of the results. An example of this is the result is that sufficient CNAs on a ward are needed. This was a result derived from the qualitative interviews with promotion groups, individual CNAs and was confirmed by the quantitative analysis of the CNA-resident ratio. Indications for the validity of the 'success of the guideline' variable come from quantitative analyses in the randomized clinical trial into the effects of the guideline on depression in demented residents (Verkaik et al., in press-a). Here it was shown that the reduction of depression severity (measured by the MDS-RAI observation scale) was larger on the successful wards than on the moderately and not-successful wards. Differences were, however, not statistically significant $(p>0.5)$, probably because of the small sizes of the subgroups in this analysis.

A limitation of the current study is the dual role of the first author: she collected most of the data and conducted most of the analyses. The first role could influence the second. A safeguard for this was the use of the fourth author in analyzing part of the data.

\subsection{Practical consequences}

In general: for a successful introduction of this or other broad care interventions a team should be sufficiently stable and the managers very well informed and enthusiastic (Benson and Dundis, 2003).

Managers should also make sure that caregivers have the right expectations of the training course.

Emotion-oriented care: for the introduction of an emotion-oriented care method a shared emotion-oriented vision is important. If this is not present, it should be established first. In addition, it is advisable to find a opinion leader: a psychologist or psychiatric nurse related to a ward/unit, who is respected, understands the specific content of the intervention and really sees it as his/her job to make the introduction a success. The involvement of family members, if possible, is also highly advisable, because of the positive and stimulating interactions they bring with them.

\section{CONCLUSIONS}

By pursuing a multiple case study design it is possible to show which factors facilitate or inhibit a successful introduction and application of the nursing guideline 'Depression in Dementia' on psychogeriatric nursing home wards. Factors influencing a successful introduction are mainly found at the first two levels of the nursing home: nursing home management (level 1) and nursing team (level 2). Factors influencing a successful application of the guideline are mainly found on the last two levels: CNAs (level 3) and residents (level 4). Most variables regarding the introduction are well known from the literature, and mainly concern the stability of the organization and team, and compatibility of the guideline with current practice and vision. Other important factors regarding the introduction and application of this and other interventions that change processes to improve and manage care for specific categories of patients, seem to be the presence of an opinion leader (a respected caregiver, related to the ward and who perceives it to be his/her personal goal to make the introduction a success) and the positive attitudes of relatives. Together they can really motivate nursing teams and other care professionals to change the way they provide care.

We studied the introduction of the nursing guideline 'Depression in Dementia'. For a real implementation its use should be consolidated. A local opinion could also play an important role in this.

\section{Conflict of interest: None.}


Verkaik, R., Francke, A.L., Meijel, B. van, Ouwerkerk, J., Ribbe, M.W., Bensing, J.M. Introducing a nursing guideline on depression in dementia: a multiple case study on influencing factors. International Journat of Nursing Studies: 2011, 48(9), 1129-1139

Funding: The study was funded by ZonMW, the Netherlands Organisation for Health Research and Development. The funders did not participate or had any influence on the research.

Ethical approval: Dutch Central Committee on Research Involving Human Subjects (CCMO), project number P04.1658.

\section{REFERENCES}

AGREE Collaboration, 2003 AGREE Collabotation, Development and validation of an international appraisal instrument for assessing the quality of clinical practice guidelines: the AGREE project, Qual. Saf. Health Care 12 (2003), pp. 18-23.

APA, 1994 American Psychiatric Association, Diagnostic and Statistical Manual of Mental Disorders. DSMIV, American Psychiatric Association, Washington (1994).

Benson and Dundis, 2003 S.G. Benson and S.P. Dundis, Understanding and motivating health care employees: integrating Maslow's hierarchy of needs, training and technology, J. Nurs. Manage. 11 (2003), pp. 315-320.

Denzin, 1978 N. Denzin, The Research Act, Aldine, Chicago (1978).

Foley et al., 2003 K.L. Foley, S. Sudha and P.D. Sloane et al., Staff perceptions of successful management of severe behavioral problems in dementia special care units, Dementia 2 (2003), pp. 105-124.

Francke et al., 2008 A. Francke, M. Smit, A. De Veer and P. Mistiaen, Factors influencing the implementation of clinical guidelines for health care professionals: a systematic meta-review, BMC Med. Inform. Decis. Mak. 8 (2008), p. 38.

Holtkamp et al., 2001 C.C. Holtkamp, A. Kerkstra, M.E. Ooms, C. van Campen and M.W. Ribbe, Effects of the implementation of the Resident Assessment Instrument on gaps between perceived needs and nursing care supply for nursing home residents in the Netherlands, Int. J. Nurs. Stud. 38 (2001), pp. 619628.

Olin et al., 2002 J.T. Olin, L.S. Schneider, I.R. Katz, B.S. Meyers, G.S. Alexopoulos and J.C. Breitner et al., Provisional diagnostic criteria for depression of Alzheimer disease, Am. J. Geriatr. Psychiatry 10 (2002), pp. 125-128.

Port et al., 2001 C.L. Port, A.L. Gruber-Baldini and L. Burton et al., Resident contact with family and friends following nursing home admission, Gerontologist 41 (2001), pp. 589-596.

Radar and Tornquist, 1995 J. Radar and E. Tornquist, Individualized Dementia Care: Creative Compassionate Approaches, Springer, New York (1995)

Reisberg et al., 1982 B. Reisberg, S.H. Ferris, M.J. de Leon and T. Crook, The Global Deterioration Scale for assessment of primary degenerative dementia, Am. J. Psychiatry 139 (1982), pp. 1136-1139.

Robison et al., 2007 J. Robison, L. Curry and C. Gruman et al., Partners in caregiving in a special care environment: cooperative communication between staff and families on dementia units, Gerontologist 47 (2007), pp. 504-515.

Rogers, 2003 Rogers, S., 2003. Continuous Quality Improvement: effects on professional patient outcomes. (Protocol for a Cochrane Review.) The Cochrane Library 2. Update Software, Oxford.

Schrijnemaekers et al., 2002 V.J. Schrijnemaekers, E. van Rossum, M.J. van Heusden and G.A. Widdershoven, Compliance in a randomized controlled trial: the implementation of emotion-orientated care in psycho-geriatric facilities, J. Adv. Nurs. 39 (2002), pp. 182-189.

Strauss and Corbin, 1998 A. Strauss and J. Corbin, Basics of qualitative research: techniques and procedures for developing grounded theory, Sage, Thousand Oaks (1998).

Teri et al., 1997 L. Teri, R.G. Logsdon, J. Uomoto and S.M. McCurry, Behavioral treatment of depression in dementia patients: a controlled clinical trial, J. Gerontol. B: Psychol. Sci. Soc. Sci. 52 (1997), pp. 159166.

Teunissen, $1985 \mathrm{~J}$. Teunissen, Triangulatie als onderzoeksstrategie in symbolisch interactionistisch onderzoek (Triangulation as research strategy in symbolic interaction research). In: W. Arts, H. Hilhorst and F. Wester, Editors, Betekenis en interactie: Symbolisch interactionisme als onderzoeksperspectief (Meaning and interaction: symbolic interactionism as research perspective), Van Loghum Slaterus, Deventer (1985), pp. 82-97.

van Weert et al., 2004 J.C. van Weert, A. Kerkstra, A.M. van Dulmen, J.M. Bensing, J.G. Peter and M.W. Ribbe, The implementation of snoezelen in psychogeriatric care: an evaluation through the eyes of caregivers, Int. J. Nurs. Stud. 41 (2004), pp. 397-409. 
Verkaik, R., Francke, A.L., Meijel, B. van, Ouwerkerk, J., Ribbe, M.W., Bensing, J.M. Introducing a nursing guideline on depression in dementia: a multiple case study on influencing factors. International Journal of Nursing Studies: 2011, 48(9), 1129-1139

Verkaik et al., in press-a Verkaik, R., Francke, A.L., Van Meijel, B., Spreeuwenberg, P.M.M., Ribbe, M.W., Bensing, J.M. The effects of a nursing guideline on depression in psychogeriatric nursing home residents. Int. J. Geriatr. Psychiatry, in press-a.

Verkaik et al., in press-b Verkaik, R., Francke, A.L., Van Meijel, B., Spreeuwenberg, P.M.M., Ribbe, M.W., Bensing, J. The introduction of $a$. nursing guideline on depression at psychogeriatric nursing home wards: effects on Certified Nurse. Assistants. Int. J. Nurs. Stud., in press-b.

\section{BOX AND TABLES}

\section{BOX 1. ELEMENTS OF THE GUIDELINE INTRODUCTION.}

\section{(1) Training and homework}

The training was provided by one of three trainers of the Centre for Training and Expertise

Osira/Bernardus from Amsterdam. Although the training was primarily focused on CNAs, the nursing team manager and occupational therapist were also invited to attend all three training sessions. This was considered important for supporting the CNAs in using the guideline. The course consisted of: three hours of training in week 1 (first training session); homework in week 2 and 3; three hours of training in week 4 (second training session); homework in weeks 5-10; a three hour follow-up training session in week 11

(follow-up training);

\section{First training session}

Core elements of the first training session, in line with the key elements of the guideline, were (1) how to increase individualized pleasant activities, and (2) how to decrease unpleasant events. Additionally, attention was paid to recognition of comorbid depression and dementia and the importance of a person centered and systematic way of working. At the end of the first training session CNAs learned which of their current residents were diagnosed by the nursing home physician or psychologist with depression in dementia. During the training session, groups of three to five CNAs were formed around each diagnosed resident. In the following weeks each group had to develop a Pleasant-Activities-Plan for their resident. Pleasant-Activities-Plans (homework)

As a first step, data about the life history, personality and preferred activities were collected from the resident and his or her family. Information was also gathered about present depressive symptoms and the contexts in which these occur. Based on the collected information, the Pleasant-Activities-Plans had to contain written information on depression symptoms and the purposes, planning and evaluation of individualized and tailor-made pleasant activities. Activities in the plan could be conducted by CNAs themselves during regular care (e.g. play preferred music or make jokes during morning care) or during additional care (e.g. walking in the garden). Activities could also be performed by occupational therapists or relatives of the resident (e.g. take the resident to shops or to the local pub), but the CNAs remained responsible for developing, facilitating and evaluating the activities.

\section{2nd and follow-up training sessions}

In the second training session the formulated Pleasant-Activities-Plans were discussed in the group. After the necessary adaptations were made, the plans were integrated into daily care and evaluated as described in the plan. In the follow-up training the experiences of the CNAs were discussed for each participating resident and plans were made for further introduction of the guideline onto the ward.

\section{(2) Promotion group}

A "promotion group" consisting of the nursing team manager, occupational therapist and two CNAs was installed, with a view to encouraging and supporting the team in following the guideline. This group could consult the trainer between weeks 1 and 11 . 
Verkaik, R., Francke, A.L., Meijel, B. van, Ouwerkerk, J., Ribbe, M.W., Bensing, J.M. Introducing a nursing guideline on depression in dementia: a multiple case study on influencing factors. International Journat of Nursing Studies: 2011, 48(9), 1129-1139

Table 1

Success of the guideline introduction.

\begin{tabular}{|c|c|c|c|c|}
\hline Ward & $\begin{array}{l}\text { Average mark for training } \\
{[\text { Min-Max }](\geq 7.5=1 \text { point; }} \\
5-7.5=0 \text { points; }<5=-1 \text { point })\end{array}$ & $\begin{array}{l}\text { Percentage of Pleasant-Activities-Plans } \\
\text { in care files }(\geq 70 \%=1 \text { point; } \\
50-70 \%=0 \text { points; }<50 \%=-1 \text { point })\end{array}$ & $\begin{array}{l}\text { Meetings of promotion } \\
\text { group ( } \geq 1=1 \text { point })\end{array}$ & $\begin{array}{l}\text { Success guideline } \\
\text { introduction }(-2 \text { to }+3)\end{array}$ \\
\hline 1 & $7.9[7-10](1)$ & $100 \%(1)$ & $2(1)$ & 3 \\
\hline 2 & $7.6[6-8](1)$ & $100 \%(1)$ & $1(1)$ & 3 \\
\hline 3 & $7.7[7-8](1)$ & $60 \%(0)$ & $3(1)$ & 2 \\
\hline 4 & $7.4[6-8](0)$ & $100 \%(1)$ & $0(0)$ & 1 \\
\hline 5 & $8.0[7-9](1)$ & $67 \%(0)$ & $0(0)$ & 1 \\
\hline 6 & $7.7[6-9](1)$ & $63 \%(0)$ & $0(0)$ & 1 \\
\hline 7 & $7.5[6-10](1)$ & $67 \%(0)$ & $0(0)$ & 1 \\
\hline 8 & $4.7[1-6](-1)$ & $56 \%(0)$ & $1(1)$ & 0 \\
\hline 9 & $6.9[5-8](0)$ & $0 \%(-1)$ & $0(0)$ & -1 \\
\hline
\end{tabular}

\section{BOX 2. TOPIC LISTS INDIVIDUAL AND GROUP INTERVIEWS.}

\section{Topic list individual interviews}

1. What were your expectations of the guideline/training?

2. How \& to whom do you apply the guideline?

3. What goes well? What does not?

4. What inhibits applying the guideline?

5. What facilitates applying the guideline?

6. How do residents respond to (parts of) the guideline?

7. How are relatives involved?

8. Are residents less depressed?

9. Atmosphere on the ward?

\section{Topic list interview promotion groups}

1. Applying the guideline: what goes well? what doesn't?

2. Do CNAs show a more emotion-oriented attitude?

3. How often are depressed and demented residents offered additional pleasant activities?

4. How often are pleasant activities integrated into regular care?

5. How often are depressed and demented residents supported when showing depressed mood?

6. What facilitated introduction/application of the guideline?

7. What inhibited introduction/application of the guideline?

8. How do residents respond to the guideline? Less depressed?

9. Future plans? 
BOX 3 DESCRIBES THE GUIDELINE INTRODUCTION ON TWO OF THE SUCCESSFUL WARDS (NOS. 1 AND 3) AND BOX 4 THE INTRODUCTION AT THE TWO UNSUCCESSFUL WARDS (NOS. 8 AND 9).

\author{
Box 3. Case descriptions of two successful wards (nos. 1, 3). \\ Successful wards \\ Ward no. 1
}

The decision to introduce the guideline came from the ward itself. A psychologist connected to the ward played an important role in the introduction. She was very enthusiastic, took part in the training sessions, promotion group meetings and supported the team [code: facilitating opinion leader]. She invented the 'buddy-principle' in which two CNAs who knew a resident well were coupled. Together the buddies were responsible for the application of a Pleasant-Activities-Plan. This worked very well. The team of this ward was very stable and cohesive [code: stable team] and had a shared emotion-oriented attitude [code: emotion-oriented care vision]. They were an enthusiastic union. One CNA described this as follows: "I think that we all enjoy working here. That you get the hug of a resident, that's the aim of us all. We are a union, yes. We laugh and cry together. This ward feels like a warm blanket.” Family members of the residents were very enthusiastic about the method [code: facilitating relatives]. They provided the CNAs with life history information and facilitated pleasant activities. One CNA: "I really liked the information and knowledge we got from the family members. We really need that. Also the positive contact. At last you can talk with relatives about something pleasurable."

The CNAs of this ward were still applying the guideline at the time that the interviews took place. The Pleasant-Activities-Plans were in the residents' care files. The CNAs saw an improvement of depression in all residents and thought that this was at least partly due to the use of the guideline [code: facilitating visible reduction of depression].

Ward no. 3

CNAs of the ward were at first sceptical about the guideline introduction. They perceived it as 'just another training course'. But when they saw that application indeed had a positive effect on the residents they became really enthusiastic. "The reactions of Ms. $\mathbf{X}$ were the best" [code: facilitating visible reduction of depression]. Also the way the training was organized was experienced as very stimulating. "Doing it together, with many practical examples was very encouraging."

The activity therapist, psychologist and team manager were all highly engaged in the guideline introduction [code: team manager recognizes relevance of guideline]. The promotion group came together every two weeks and the nursing home's policy day was dedicated to the guideline introduction. Now, after the guideline introduction, CNAs ask the psychologist earlier for help, and the activity therapist reports that she is now more involved with the daily care of the residents. The team manager reports that the nursing home management has plans for introducing the guideline throughout the entire nursing home. 
Verkaik, R., Francke, A.L., Meijel, B. van, Ouwerkerk, J., Ribbe, M.W., Bensing, J.M. Introducing a nursing guideline on depression in dementia: a multiple case study on influencing factors. International Journa of Nursing Studies: 2011, 48(9), 1129-1139

\section{BOX 4. CASE DESCRIPTIONS OF THE TWO UNSUCCESSFUL WARDS (NOS. 8 AND 9). Unsuccessful wards \\ Ward no. 8}

The decision to participate in the guideline introduction was made by a nursing-home physician and team manager who at the time of the guideline introduction were no longer connected to the ward. The new team manager did not see the value of the guideline introduction [code: inhibiting; team manager does not recognize relevance of guideline]. When some CNAs mentioned positive effects of the introduction at the end of the third training session, the team manager denied these. This happened just before the CNAs were asked to give their level of appreciation to the training course $(0=$ very low; $10=$ very high $)$. The average appreciation score then given was 4.7 !

CNAs had also expected another type of guideline and training. They expected to receive ready-made solutions for individual residents and not a guideline that showed them how to develop and apply their own care plans [code: inhibiting expectation to receive instant solutions for depression]. A CNA exclaims "Now we had to do even more!". They also said that they already applied the method. One CNA states "There was nothing new on it, no new possibilities or methods, we all already did this." This ward developed Pleasant-Activities-Plans, but none of the principles of the guideline were followed.

Ward no. 9

The management of the nursing home, together with the team manager of the ward, had decided to participate in the study. Despite the fact that the research team had warned the management not to introduce other methods or have other training courses during the guideline introduction, a new reporting system was introduced and another training course was given [code: inhibiting; other innovations at the time of the guideline introduction]. The team manager of the ward tells"...in the same period we were burdened with some other training courses that were appointed by the nursing home management. Three new methods were introduced at the same time!"

The team of this ward had shortage of staff [code: inhibiting shortage of personnel] during the whole introduction period. The team manager explained the effect on the guideline introduction and application "...because if you are so short of personnel as we were...You can do the work if there are seven CNAs, the quality of care rises with eight. If I tell you that we had to do the work with five, than it is clear that we gave priority to group activities instead of individual..."

Many of the family members did not want to provide the CNAs with life history information of their relatives [code: inhibiting attitudes of family members], probably because of prior negative relationships. According to the CNAs it was therefore very difficult or impossible to develop individualized PleasantActivities-Plans.

The CNAs of this ward developed a Pleasant-Activities-Plan for every resident during the training (information form training reports), but none of the plans could be found in the care files at the time the interviews were held. Interviewed CNAs stated that they had applied the plans, but did not see effects on depression [code: inhibiting; no visible reduction of depression]. 
Verkaik, R., Francke, A.L., Meijel, B. van, Ouwerkerk, J., Ribbe, M.W., Bensing, J.M. Introducing a nursing guideline on depression in dementia: a multiple case study on influencing factors. International Journat of Nursing Studies: 2011, 48(9), 1129-1139

Table 2

Inhibiting and facilitating factors per ward.

\begin{tabular}{|c|c|c|c|c|c|c|c|c|c|c|}
\hline & \multirow{2}{*}{$\begin{array}{l}\text { Inhibiting and facilitating factors for } \\
\text { guideline introduction }\end{array}$} & \multicolumn{9}{|c|}{ Present and ward no. } \\
\hline & & 1 & 2 & 3 & 4 & 5 & 6 & 7 & 8 & 9 \\
\hline \multicolumn{11}{|c|}{ Level 1. Nursing home management } \\
\hline Inhibiting factors & $\begin{array}{l}\text { - reorganizations or other innovations } \\
\text { at the time of the guideline introduction } \\
\text { - top down introduction of the guideline }\end{array}$ & & & & & & & $\bullet$ & & $\bullet$ \\
\hline \multicolumn{11}{|c|}{ Level 2. Nursing team } \\
\hline Facilitating factor & $\begin{array}{l}\text { - presence of an opinion leader } \\
\text { - a reporting system that the guideline } \\
\text { fits into }\end{array}$ & $\bullet$ & $\bullet$ & & & & & & & \\
\hline \multirow[t]{5}{*}{ Inhibiting factors } & $\begin{array}{l}\text { - team manager does not recognize } \\
\text { relevance of guideline introduction } \\
\text { - high staff turnover }\end{array}$ & & & & & $\bullet$ & & & $\bullet$ & \\
\hline & $\begin{array}{l}\text { - shortage of certified personnel } \\
\text { - not sharing an emotion-oriented care vision }\end{array}$ & & & & $\bullet$ & & & $\bullet$ & & $\bullet$ \\
\hline & $\begin{array}{l}\text { - view: 'depressed residents must not } \\
\text { have more privileges than non-depressed } \\
\text { residents' }\end{array}$ & & & & & & $\bullet$ & & $\bullet$ & \\
\hline & $\begin{array}{l}\text { - expectation: expecting instant solutions } \\
\text { for depression }\end{array}$ & & & & & & & & $\bullet$ & \\
\hline & $\begin{array}{l}\text { - not training non-certified or non-registered } \\
\text { caregivers }\end{array}$ & $\bullet$ & $\bullet$ & $\bullet$ & $\bullet$ & $\bullet$ & $\bullet$ & $\bullet$ & $\bullet$ & $\bullet$ \\
\hline
\end{tabular}

